\title{
¿HAY QUE INCORPORAR A NIETZSCHE A LA HERMENÉUTICA? RAZONES DE UNA PEQUEÑA RESISTENCIA
}

\author{
Should hermeneutics incorporate Nietzsche's thought? \\ Arguments for a little resistance
}

Jean Grondin

Université de Montréal

RESUMEN: El tema del lugar de Nietzsche en la hermenéutica implica varias cuestiones: ¿̇el pensamiento de Nietzsche puede ser caracterizado como "hermenéutico», y en qué medida, dado que la hermenéutica sólo ha sido desarrollada como tal después de él? ¿Puede y debe la hermenéutica, que hasta hace poco no ha tenido muy en cuenta su pensamiento, incorporarlo todo entero? Si bien una fecundación mutua sería siempre fructífera, este trabajo defiende que deberíamos resistir frente a la integración simple de Nietzsche en la hermenéutica, teniendo en cuenta su diferente manera de entender la verdad, la interpretación y el nihilismo. De este modo también se hace posible una resistencia frente a la concepción postmoderna y nihilista de la hermenéutica. Siendo conscientes de sus diferencias, la hermenéutica y Nietzsche tendrían mucho que contribuir uno a otro.

Palabras clave: verdad - interpretación - nihilismo - hermenéutica - postmodernismo

ABSTRACT: The question of Nietzsche's place in hermeneutics raises many questions: can Nietzsche's thought itself be characterized as «hermeneutical» and, to what extent, given that hermeneutics was only developed as such after him? Can and should hermeneutics, which until recently did not take his thought much into account, incorporate Nietzsche's thought as a whole? Whereas a mutual fecundation will always be fruitful, this paper argues that one should resist a simple integration of Nietzsche into hermeneutics in light of their different understandings of truth, interpretation and nihilism. It thus becomes possible to also resist the postmodern and nihilistic understanding of hermeneutics. Aware of their differences, hermeneutics and Nietzsche will perhaps have more to say to one another.

Keywords: Truth - Interpretation - Nihilism - Hermeneutics - Postmodernism

«Nietzsche y la hermenéutica», el tema de nuestro coloquio, es ciertamente el título de un extraordinario reto filosófico. Suponiendo que cada uno tuviese una idea clara de lo que significan los nombres de Nietzsche y de la hermenéutica, puesto que en ambos casos eso es todo salvo evidente, ¿cómo hay que comprender el «y» que se propone reunirlos? A Fichte le gustaba decir de la conjunción «y» que se trataba de la palabra menos filosófica que existía: mera yuxtaposición, que no establece ningún vínculo, ninguna deducción, entre los términos que piensa a la vez, y que puede entenderse de varias formas diferentes: $a$ ) puede entenderse en el sentido de una simple continuación o de una sucesión temporal (como en la expresión "Kant y el idealismo alemán»); $b$ ) puede verse también en ella una alternativa tajante (el capitalismo y el comunismo, Heidegger y Carnap), pero también $c$ ) una conexión más natural, e incluso explicativa (Husserl y la 
fenomenología, Einstein y la teoría de la relatividad, etc.). ¿Es en este sentido en el que hay que entender el título «Nietzsche y la hermenéutica»?

Existe ahí una tensión, perfectamente filosófica, que puede abordarse bajo diversos ángulos, partiendo unas veces de Nietzsche, otras de la hermenéutica, y de aquello que es susceptible de acercar el uno a la otra.

\section{1. ¿HAY QUE «NIETZSCHEANIZAR» LA HERMENÉUTICA?}

Se trataría, en este último caso, de mostrar que las perspectivas de Nietzsche y las de la hermenéutica, aunque ajenas, si echamos una primera ojeada, son compatibles, o, más modestamente, podrían enriquecerse mutuamente. Desde esta perspectiva, podríamos preguntarnos, por una parte, si Nietzsche es «hermeneutizable». Tomo prestado el adjetivo de Jesús Conill, quien se pregunta en uno de sus últimos libros si hay un Kant hermenéutico o "hermeneutizable» ${ }^{1}$, es decir, susceptible de ser recuperado por la hermenéutica o puesto de acuerdo con ella. Además, Jesús Conill ha querido mostrar en un trabajo más antiguo, y excelente, sobre Nietzsche y el poder de la mentira, que existen efectivamente puentes entre Nietzsche y la hermenéutica ${ }^{2}$. La tendencia consiste aquí en el acercamiento de los dos universos de pensamiento. Pero podríamos preguntarnos, por otra parte, si la hermenéutica puede o debe ella misma «nietzscheanizarse». Esto querría decir que habría en la hermenéutica misma elementos susceptibles de ser comprendidos en un sentido más nietzscheano o que ganarían al serlo. También, desde este punto de vista, Jesús Conill se muestra bastante favorable a esta «nietzscheanización» de la hermenéutica.

¿Pero para quién representarían una ganancia esta «hermeneutización» (de Nietzsche) o esta «nietzscheanización» (de la hermenéutica)? ¿Necesita la hermenéutica de Nietzsche? ¿Puede ayudarle a ser mejor? Por lo que se refiere a Nietzsche, ¿se volvería más contundente si se encontrara «enhermeneutizado»? No diría que se tratase en este caso de una urbanización, pero podría ser que su pensamiento perdiese entonces su tono tajante, y sin duda su atracción para algunos.

Sobre este asunto, soy un poco más escéptico que mi colega Jesús Conill, aunque he aprendido enormemente de sus trabajos. Lo que me parece es que la hermenéutica ha llegado al momento presente (éste no era el caso hace treinta años) ya bastante «nietzscheanizada» y que no tiene mucha necesidad de serlo más. Me refiero aquí a la constelación más reciente de la hermenéutica, dominada, creo, por autores como Richard Rorty y Gianni Vattimo, quienes han querido leer la hermenéutica en un sentido totalmente relativista («no hay hechos, sólo interpretaciones») y, por tanto, muy nietzscheano. En el caso de Vattimo esta «nietzscheanización de la hermenéutica» ha sido incluso admitida y promovida abiertamente, puesto que se trata de un intérprete sagaz de Nietzsche (y de Heidegger $)^{3}$. Modificándola en el sentido de un relativismo, e incluso de un nihilis-

1. J. Conill, Ética hermenéutica, Madrid: Tecnos, 2006, p. 19: «¿Hay un Kant hermenéutico o hermeneutizable?».

2. J. Conill, El poder de la mentira. Nietzsche y la política de la transvaloración, Madrid: Tecnos, 1997, sobre todo el capítulo II: «Nietzsche y la hermenéutica contemporánea».

3. Cf. por ejemplo G. Vattimo, Il soggetto e la maschera: Nietzsche e il problema della liberazione, Milano: Bompiani, 1974, y Dialogue with Nietzsche, New York: Columbia University Press, 2005. 
mo, Vattimo trata de dar un giro nietzscheano a la hermenéutica ${ }^{4}$, si no trata de borrar las diferencias entre ambas.

Comprendo que haya acercamientos, aclaraciones, entre Nietzsche y la hermenéutica y que el diálogo sea siempre una virtud, pero, en mi modesta opinión, considero que es tiempo de resistir en buena medida a esta nietzscheanización, puesto que tiende a borrar las diferencias importantes que existen entre ambos pensamientos. Jacques Derrida lo había ya presentido en L'écriture et la différence al encomendarse a Nietzsche y a su celebración del juego de los signos para disociarse de todo pensamiento "hermenéutico» que busca descifrar un sentido ${ }^{5}$. Derrida veía en la oposición entre «Nietzsche y la hermenéutica» una alternativa exclusiva, y lo hacía para defender el auténtico fundamento (si puede llamarse así) de la práctica nietzscheana de la interpretación (la afirmación del juego plural de los signos en detrimento del desciframiento del sentido). Aun reconociendo que pueden establecerse puentes entre ambos, pienso que la idea derridiana de un antagonismo irreconciliable puede mantenerse, pero para defender a la hermenéutica frente a una posible deriva nietzscheana. Sin dudar en absoluto del genio filosófico de Nietzsche, que nadie iguala en la hermenéutica, sería de la opinión de quienes piensan que es posible resistir a una nietzscheanización demasiado forzada de la hermenéutica, en todo caso en el sentido en que la entienden Vattimo y Rorty.

Con el propósito de arrojar un poco de luz sobre esta relación compleja, quisiera comenzar por recordar algunos hechos bastante banales (puesto que considero que no hay sólo interpretaciones, sino también hechos) sobre el lugar de Nietzsche en la hermenéutica y sobre el lugar de la hermenéutica en Nietzsche.

\section{NIETZSCHE ESTÁ BASTANTE AUSENTE DE LA TRADICIÓN HERMENÉUTICA}

Ante todo es bastante evidente que Nietzsche no forma o no formó parte de la tradición clásica de la hermenéutica, es decir, de la catena aurea que reunirá nombres como los de Schleiermacher, Dilthey, Heidegger, Gadamer y Ricoeur. Cronológicamente, podría situarse a Nietzsche entre Dilthey y Heidegger, pero la mayoría de los historiadores de la hermenéutica no dan cuenta realmente de su contribución a la hermenéutica (hay excepciones). Los dos principales representantes de la hermenéutica contemporánea, Gadamer y Ricoeur, han tratado muy poco de Nietzsche, aunque lo conocían bien. Ricoeur lo nombra entre los maestros de la sospecha, con Freud, Marx y Lévi-Strauss, pero ha hablado mucho más de estos tres autores que de Nietzsche. Gadamer no ha consagrado más que dos estudios, tardíos, a Nietzsche, «Nietzsche - el antípoda. El drama de Zaratustra» [1984] (GW IV, pp. 448-462) y «Nietzsche y la metafísica» $(1999)^{6}$

4. Cf. mi estudio «Vattimo's Latinization of Hermeneutics. Why Did Gadamer Resist Postmodernism?», en S. Zabala (dir.), Weakening Philosophy. Essays in Honor of Gianni Vattimo, Montreal/Kingston: McGill-Queen's University Press, 2007, pp. 203-216, donde intenté mostrar lo que esta lectura tenía de problemático.

5. Cf. J. Derrida, «La structure, le signe et le jeu dans le discours des sciences humaines», en L'Écriture et la différence, Paris: Seuil, 1967, p. 411. Cf. al respecto mi librito ¿̇Qué es la hermenéutica?, Barcelona: Herder, 2008, pp. 127-132.

6. Aparecido en su último libro, publicado en 2000, Hermeneutische Entwürfe, Tübingen: Mohr Siebeck, pp. 134-142; trad. de A. Agud y R. de Agapito en Acotaciones hermenéuticas, Madrid: Trotta, 2002, pp. 169-180. 
(estudio donde se habla más de Heidegger que de Nietzsche). Pero ninguno de estos estudios nos permite pensar que Nietzsche haya constituido una real e importante fuente de inspiración para Gadamer. No sucede así con Heidegger, quien ha consagrado numerosos cursos, varios estudios y dos tomos importantes a la figura de Nietzsche (tomos que debían titularse "La metafísica de Nietzsche», como lo revela la correspondencia, todavía inédita, entre Heidegger y Otto Pöggeler $\left.{ }^{7}\right)$. Sin embargo, el autor de los tomos de Nietzsche pretende únicamente despedirse del pensamiento «transcendental y hermenéutico» en beneficio del pensamiento de la historia del $\operatorname{ser}^{8}$. Es otra forma de decir que el Heidegger que se inspira en Nietzsche no lo hace desde la perspectiva del pensamiento «hermenéutico", sino desde la perspectiva de la historia del ser. Además, en esta historia del ser, Nietzsche aparece más como un adversario que como un aliado para Heidegger: es Nietzsche quien habría llevado a la cima el pensamiento "metafísico», el cual se habría caracterizado por una voluntad de dominación del ser en su conjunto capaz de resumir el pensamiento del ser en términos de «valor» y la noción misma de «voluntad de poder». Sea o no exacta esta interpretación de la voluntad de poder, es evidente que Heidegger trata, por su parte, de renunciar a esta voluntad de la voluntad, en nombre de la «serenidad» (Gelassenheit) del pensamiento del ser, que deja ser al ser en lugar de someterlo a los dictados de la voluntad. Nietzsche no es pues para Heidegger un aliado real. Por lo demás, en una confesión hecha a sus más allegados, Heidegger dijo en un determinado momento: "Nietzsche hat mich kaputtgemacht», "Nietzsche me ha destruido»"

\section{NIETZSCHE HABLA POCO DE HERMENÉUTICA, PERO MUCHO DE FILOLOGÍA}

Si la tradición de la hermenéutica ha ignorado con frecuencia la figura de Nietzsche (hay excepciones, entre ellos J. Figl ${ }^{10}$ y J. Conill), esta ignorancia es recíproca, puesto que el mismo Nietzsche ha hablado bastante poco de la hermenéutica como tal. Es cierto que en vida de Nietzsche la hermenéutica no gozaba de una gran visibilidad. Las cosas no han cambiado sino con Heidegger y Gadamer. Ahora bien, como especialista de filología clásica, Nietzsche no ignoraba su existencia. En sus cursos de introducción a la filología clásica, Nietzsche evoca de hecho en un momento determinado la hermenéutica: «El método que consiste en comprender y en juzgar lo transmitido por la tradición implica dos partes [...]. La crítica se refiere a la transmisión (Überlieferung). La hermenéutica a lo transmitido (das Überlieferte)» ${ }^{11}$. Alan D. Schrift tiene razón al recordar que Nietzsche sigue aquí la terminología del filólogo F. A. Wolf (1759-1824), uno de los funda-

7. Martin Heidegger / Otto Pöggeler. Briefwechsel 1957-1976, ed. de K. Busch y C. Jamme, en prensa.

8. M. Heidegger, Nietzsche, Pfullingen: Neske, 1991, t. 2, p. 415.

9. Cf. las interpretaciones que Gadamer, Müller-Lauter, Pöggeler y von Herrmann proponen de esta confesión en la revista Aletheia 5 (1994), 6-8 y 9/10 (1996), 19-26.

10. J. Figl, «Nietzsche und die philosophische Hermeneutik des 20. Jahrhunderts. Mit besonderer Berücksichtigung Diltheys, Heideggers und Gadamers»: Nietzsche-Studien 10-11 (1981-1982), 408-430.

11. KGW II/3 374-375. Sobre estos textos, cf. A. D. Schrift, Nietzsche and the Question of Interpretation. Between Hermeneutics and Deconstruction, London/New York: Routledge, 1990, p. 161. 
dores de las ciencias de la Antigüedad clásica (klassische Altertumswissenschaften). Además, las disciplinas de la crítica y de la hermenéutica han preocupado a los autores que se han interesado por los fundamentos de las ciencias filológicas en los siglos XVIII y XIX. Con los teólogos (como Schleiermacher, además filólogo), eran poco más o menos los únicos en aquella época que sabían lo que era la hermenéutica. La crítica (ars critica) y la hermenéutica (hermeneutica, Auslegekunst) constituían pues las dos ciencias auxiliares de la filología: la crítica era la ciencia de la edición «crítica» de los textos de la Antigüedad clásica, basada en la crítica de las fuentes, es decir, en el examen atento de los estratos de transmisión, mientras que la hermenéutica se interesaba en el modo en que esos textos, una vez editados, llegaban a ser interpretados, y más en particular en las reglas de interpretación. Es en este sentido en que el joven Nietzsche dijo de la crítica que se interesa en la "transmisión» (Überlieferung) de los textos y la hermenéutica en aquello que ha sido transmitido (das Überlieferte). Pero la distinción no gozaba de un peso especial en Nietzsche y se encuentra por tanto poco si no ninguna ocurrencia significativa del término hermenéutica en su corpus.

No es menos interesante señalar que Nietzsche se ha enfrentado con todas las disciplinas que llevaron la hermenéutica hasta el siglo XX:

a) La teología. No sólo Nietzsche era hijo de pastor, sino que toda su primera Consideración intempestiva se apoyaba en el teólogo Friedrich David Strauss. Conoció también a Schleiermacher ${ }^{12}$ y su influencia, y había concebido el proyecto de redactar una (quinta) consideración intempestiva sobre la religión, tema del que por otra parte trató mucho en sus obras ulteriores, y en una perspectiva tan visceralmente crítica que traiciona una secreta fascinación;

b) La historia. Gran pensador de la genealogía (que influirá en Foucault en este aspecto), Nietzsche escribió mucho sobre la historia, particularmente en su Segunda consideración intempestiva sobre el prejuicio y la utilidad de la historia para la vida (de la que podemos decir que se trataba de una perspectiva «hermenéutica» sobre la disciplina). Había leído también a los grandes historiadores de su tiempo, a Ranke y a Droysen, los cuales abordaron los problemas de interpretación y de metodología que planteaban las ciencias históricas; la Segunda intempestiva se inscribe, por lo que se ve, aunque lo hace de forma crítica, en la línea de estas reflexiones «metateóricas» sobre la historia;

c) La filología clásica. Se trata, como cada uno de nosotros sabe, de la primera formación de Nietzsche. Si es cierto que la procedencia es testimonio del futuro (Herkunft bleibt Zukunft), puede decirse que su lectura suspicaz y «rumiante» es un legado de su formación de filólogo. Si se sustituyera en sus textos el término de filología por el de hermenéutica, no hay duda de que encontraríamos en él un pensamiento de un auténtico alcance hermenéutico. En este sentido podría hablarse de la contribución «silenciosa» de Nietzsche a la hermenéutica. Recordaría los grandes rasgos y los grandes temas, pero lo haría desde una perspectiva crítica, con el fin de explicar por qué me parece oportuno interponer una pequeña resistencia a una incorporación pura y simple de su pensamiento al de la hermenéutica (resistencia que podría ser también la de algunos nietz-

12. Como lo revela el juego de palabras, de un gusto dudoso, de Ecce homo (KGW VI/3 359,3) a propósito de los filósofos alemanes, todos los cuales no serían más que «Schleiermacher» (es sind Alles blosse Schleiermacher), entiéndase «fabricantes de velos». 
scheanos; además de Derrida podríamos pensar aquí en Günter Abel ${ }^{13}$ que procura disociar su filosofía más nietzscheana de la interpretación del pensamiento hermenéutico).

\section{PERSPECTIVISMO E INTERPRETACIÓN}

Ambos son temas que han sido muy tratados tanto por Nietzsche como por la hermenéutica. Nietzsche repite a menudo que no hay más que una visión perspectivista de lo real. Con Alan D. Schrift, puede distinguirse el sentido de los términos de interpretación y de perspectivismo en su obra. La perspectiva designa ante todo el punto de vista que nos hace ver lo real bajo tal o cual aspecto, pero que escapa a nuestro control. Este perspectivismo es de naturaleza a la vez fisiológica, puesto que caracterizaría ya nuestro aparato sensorial, instintiva, porque concierne al orden de las necesidades, de los afectos y de las emociones, pero es también socio-histórico, al ser imputable a nuestra educación, a nuestra formación y a nuestros prejuicios, incluidos los de los filósofos. Nietzsche cumple aquí un trabajo real de Aufklärung y de genealogía, que se sitúa en el ambiente del cientificismo de su tiempo, aunque se trata de un espíritu que critica también si llega el caso (de donde la ambigüedad de la Aufklärung practicada por él). Por su parte, la interpretación, siempre siguiendo los análisis minuciosos de Alan Schrift, designa más bien nuestra puesta en orden de estas perspectivas, la forma que les damos a través de nuestras creencias, nuestras opiniones y nuestras teorías. La interpretación representa aquí un proceso más activo, más consciente, que el simple perspectivismo. Comporta también un espacio de juego mayor, valorizado por Nietzsche: cuanto más artista o filósofo se es, más se interpreta.

Estas nociones de perspectiva y de interpretación son por otra parte familiares a la hermenéutica, clásica y contemporánea. En este sentido, la relación entre Nietzsche y la hermenéutica parece natural, pero hay que desconfiar aquí de los acercamientos demasiado rápidos. La perspectiva designa la mayoría de las veces en Nietzsche la del sujeto que percibe o la del intérprete mismo. Ahora bien, en la hermenéutica clásica, la perspectiva designa en primer lugar el punto de vista del autor (o del texto) que se busca interpretar. Como he recordado en L'universalité de l'herméneutique, la perspectiva corresponde aquí al Sehe-pukct, pero también al scopus, a la intención del texto que se trata de comprender. La perspectiva se encuentra pues más en el objeto, y en su verbum interius, que en el sujeto. La toma en consideración de la perspectiva del autor (o del texto), entendida como condición de la objetividad, es además lo que permite al intérprete revisar su comprensión. Entonces es posible una «resistencia» del objeto a las interpretaciones que podrían proponerse. Ahora bien, si la perspectiva no se sitúa más que del lado del intérprete, no se ve verdaderamente lo que podría contenerlas. De ahí el abandono, fatal a mi parecer, de la idea de objetividad, e incluso de verdad, en Nietzsche y en varios de sus herederos.

Podría pensarse que la hermenéutica contemporánea de Heidegger y de Gadamer está bastante nietzscheanizada, en la medida en que insiste en la es-

13. G. Abel, Interpretationswelten. Interpretationsphilosophie jenseits von Essentialismus und Relativismus, Frankfurt a. M.: Suhrkamp, 1993. 
tructura de anticipación (Vorstruktur) y los ineludibles «prejuicios» (Vorurteile) del intérprete. Ahora bien, se ha subrayado muy poco que ambos autores lo hacían con una intención crítica y con el fin de distinguir los prejuicios legítimos, que corresponden a la cosa, de los prejuicios ilegítimos, que no son conformes con ella. La idea de adecuación sigue estando aquí presupuesta. Dos textos muy conocidos bastarán para confirmarlo. 1) En el célebre parágrafo de Ser y tiempo (\$32) donde se habla del círculo de la comprensión, Heidegger dice con toda claridad que la «tarea primera, última y constante de la interpretación consiste en no dejarse imponer nunca por ocurrencias propias o por conceptos populares ni la posición, ni la previsión ni la anticipación (Vorhabe, Vorsicht, Vorgriff), sino en asegurar la elaboración del tema científico desde la cosa misma». El propósito de la interpretación (Auslegung) en Heidegger es además siempre sacar en claro, con una intención de aclaración, las anticipaciones de la comprensión (Verstehen) con el fin de ver si están de acuerdo con los fenómenos, que la «fenomenología» promete presentar «tal como se presentan en sí mismos». 2) Cuando Gadamer se inspira en este pasaje para presentar su propia concepción hermenéutica en Verdad y método, el acento recae también mucho menos en la determinación insalvable de nuestros prejuicios que en su rectificación, que es siempre posible, deseable e incluso necesaria si no queremos quedar encerrados en el círculo de nuestros prejuicios: «El que intenta comprender está expuesto a los errores de opiniones previas que no se comprueban en las cosas mismas. Elaborar los proyectos correctos y adecuados a las cosas, que como proyectos son anticipaciones que deben confirmarse 'en las cosas', tal es la tarea constante de la comprensión»" ${ }^{14}$. Esto corresponde exactamente con la idea clásica de adecuación. Gadamer subraya en efecto que los prejuicios deben demostrarse (sich bewähren), probarse y confirmarse por las cosas mismas. Estos pasajes no les gustarán demasiado a los autores más postmodernos, más nietzscheanos. Pero son efectivamente de Gadamer y de Heidegger. Aquí me parece pues indebido querer «nietzscheanizar» más a Gadamer o a Heidegger. Por otro lado, cuando ellos elaboran sus teorías sobre la estructura de anticipación del intérprete, en Ser y tiempo o en Verdad y méto$d o$, no discuten en particular las ideas de Nietzsche. El acento no se apoya en el perspectivismo universal del comprender, poco crítico por lo demás, sino en la revisión que les hace pasar la prueba de las cosas mismas.

14. H.-G. Gadamer, Verdad y método, trad. de A. Agud y R. de Agapito, Salamanca: Sígueme, 1977, p. 333. Cf. el conjunto del contexto en Wahrheit und Methode, GW I, pp. 271-272, donde subrayo los ecos de la noción de adecuación: «Daß jede Revision des Vorentwurfs in der Möglichkeit steht, einen neuen Entwurf von Sinn vorauszuwerfen, daß sich rivalisierende Entwürfe zur Ausarbeitung nebeneinander herbringen können, bis sich die Einheit des Sinnes eindeutiger festlegt; daß die Auslegung mit Vorbegriffen einsetzt, die durch angemessenere Begriffe ersetzt werden: eben dieses ständige Neuentwerfen, das die Sinnbewegung des Verstehens und Auslegens ausmacht, ist der Vorgang, den Heidegger beschreibt. Wer zu verstehen sucht, ist der Beirrung durch Vor-Meinungen ausgesetzt, die sich nicht an den Sachen selbst bewähren. Die Ausarbeitung der rechten, sachangemesseneren Entwürfe, die als Entwürfe Vorwegnahmen sind, die sich 'an den Sachen' erst bestätigen sollen, ist die ständige Aufgabe des Verstehens. Es gibt hier keine andere 'Objektivität' als die Bewährung, die eine Vormeinung durch ihre Ausarbeitung findet». 


\section{5. ¿LA VERDAD ES UNA FORMA DE ERROR?}

Esta distinción crítica se manifiesta en el hecho de que Gadamer y Heidegger no han renunciado de ningún modo a la noción de verdad, de la que Nietzsche parece haberse despedido cuando dice que es aquella especie de error sin la cual una especie determinada de seres vivientes no podría vivir. Salvo error, «verdad» es la primera palabra en el título Verdad y método y Heidegger no ha descansado de meditar, tanto en sus cursos como en sus escritos, "la esencia de la verdad» (Vom Wesen der Wahrheit). Resulta difícil pues hablar aquí de un abandono de la idea de verdad (o de la cuestión de la esencia). En efecto, Heidegger defiende una concepción «nueva» de la verdad, como desvelamiento (idea que es sin embargo bastante clásica) y como aletheia. Ahora bien, esta aletheia, es su originalidad, aunque esta concepción se encontraba ya en la idea de una verdad ontológica en san Agustín y santo Tomás, es siempre la del ser o de las cosas mismas: es el ser que emerge (physis) y se revela. Heidegger lo dice con el fin de perturbar la concepción que se contentaba con hacer de la verdad una prerrogativa del conocimiento humano o del sujeto (como es el caso del perspectivismo nietzscheano): anterior a la relación cognitiva y verdadera con las cosas, existe un aparecer, un autodescubrimiento (Unverborgenheit) del ser mismo. Se encuentra aquí demasiado precipitadamente un cuestionamiento de la idea tradicional de verdad. Heidegger no critica ciertamente la noción de verdad como correspondencia, busca sólo mostrar que ésta es derivada, en la medida en que presupone un aparecer más original todavía que el ser, comprendido con la ayuda de la noción de aletheia (cuyo sentido variará en la obra de Heidegger: mientras que en Sein und Zeit la verdad consiste en «arrancar», o hurtar, la verdad de los recubrimientos de los que es objeto - siempre pues en nombre de un ideal de adecuación-, el desvelamiento y el velamiento participarán más tarde del acontecimiento mismo del ser; conocemos el juicio severo que Ernst Tugendhat ha dirigido, no sin razón, contra esta concepción tardía de la verdad ${ }^{15}$ ). Heidegger no discute pues que la verdad del conocimiento, que existe efectivamente, debe entenderse en el sentido de la adecuación, sino que sobre todo Heidegger la presupone en todo momento cuando habla de una destrucción de la tradición metafísica. No se puede «destruir» una tradición más que porque se juzga que es inadecuada y que una mejor debe proponerse. La verdad adecuación se mantiene pues en hermenéutica.

Nietzsche desea, por su parte, despedirse de la idea o de la «fábula» de la verdad. ¿La verdad no sería más que un error? Lo que sorprende aquí es que esta misma idea de fábula o de error presupone la noción de verdad que ella trata de criticar. No se puede hablar de «error» (o de deformación) más que en nombre de una concepción de la verdad como adecuación. Esto es también cierto cuando se critica la noción de la verdad como adecuación: no se puede en efecto denunciarla por juzgarla inadecuada... La hermenéutica se muestra entonces más consecuente cuando salvaguarda la idea de adecuación. Por lo que se refiere a la hermenéutica más nietzscheana, la cual quisiera renunciar a la idea de adecuación (Vattimo), comete una autocontradicción estridente, y esto al menos de dos maneras: 1) sostiene, con toda la seriedad del mundo, que la concepción

15. E. Tugendhat, Der Wahrheitsbegriff bei Husserl und Heidegger, Berlin: Walter de Gruyter, 1967. 
de la verdad adecuación es inadecuada, y 2) presenta su propia concepción como adecuada y justa.

\section{HAY HECHOS Y NO SÓLO INTERPRETACIONES}

En cuanto a la idea nietzscheana según la cual no hay hechos, sino sólo interpretaciones, a la que algunos tratan de reducir la hermenéutica, siempre he pensado que podría refutarse evocando los hechos más simples: la capital de España no es Copenhague, sino Madrid, nunca he ido a Saturno, una molécula de agua comprende dos y no tres átomos de hidrógeno, esta persona padece un cáncer, y no hay armas de destrucción masiva en Iraq. Esta idea de adecuación se encuentra presupuesta hasta en nuestros comportamientos más cotidianos: si queremos saber si llueve o no, basta con mirar por la ventana. Podrían multiplicarse los ejemplos. Desde luego, algunas de estas afirmaciones son falibles: podría darse, teóricamente, que un día se encontraran armas de destrucción masiva en Iraq, pero este descubrimiento revelaría que nuestra concepción inicial era errónea e inadecuada.

En su debate con G. Vattimo, René Girard considera que la declaración según la cual «no hay hechos, sino sólo interpretaciones» es, en el mejor de los casos, una broma con la que Nietzsche trataba de provocar a sus colegas filólogos demasiado positivistas, los cuales olvidaban a veces que sus hechos, la mayoría de las veces, no eran más que el resultado de interpretaciones ${ }^{16}$. Esta broma es de buena lid, pero presupone a su vez la idea de adecuación: los filólogos se equivocan al pensar que no tienen que vérselas con los hechos, cuando no están más que en presencia de sus interpretaciones.

El perspectivismo radical de Nietzsche plantea que el sentido que comprendemos no procede más que de la subjetividad, o de la «voluntad», la cual «crea» este sentido. ¿Pero es esto efectivamente verdadero? ¿Verdaderamente constituimos los objetos que interpretamos? Si esto fuera verdadero, podríamos interpretar todos los objetos de todas las formas posibles, lo que es manifiestamente imposible. Al atribuir toda creación de sentido a la subjetividad, Nietzsche se inscribe dentro del horizonte del pensamiento moderno y de su nominalismo, el cual plantea que el mundo en sí no tiene sentido en sí, no habiendo sido este sentido más que «inventado» por nuestro espíritu. Para Kant, esta donación de sentido procedía de las categorías a priori de nuestro espíritu, las cuales formalizan lo diverso desordenado que me proporciona la percepción. Nietzsche individualiza esta formalización atribuyéndola al sujeto particular y a su aparato sensorial. El «nominalismo» consiste en negar que haya esencias o realidades en el orden de los objetos mismos, puesto que estas esencias o estas regularidades no serían establecidas más que por el pensamiento. Lo real mismo se reduciría entonces al choque ciego de masas físicas que no tendrían sentido más que para

16. R. Girard, «No sólo interpretaciones, existen también los hechos», en R. Girard y G. Vattimo, Verità o fede debole. Dialogo su cristianesimo e relativismo, ed. de P. Antonello, Massa: Transeuropa, 2006, p. 82: "Esta frase es fruto de una brillante polémica con los vetero-positivistas que estaban convencidos de proferir una verdad científica inmortal cada vez que abrían la boca. Pero la boutade de Nietzsche no puede ciertamente funcionar como una teoría de la interpretación: no tener otra cosa más que interpretaciones es lo mismo que no tener ninguna». 
el observador que las reconociese o, según Nietzsche, que introdujese en ellas un significado. Así pues, el sentido de las cosas no puede proceder más que «del exterior», en este caso del sujeto o de su voluntad de poder (volveremos al instante sobre este término).

¿Pero es correcto sostener que no hay sentido en el mundo y que este sentido no es introducido más que por nosotros? Siempre me ha parecido que sorprendentemente se sobreestimaba aquí la contribución de nuestra tímida subjetividad. ¿Por qué no reconocer que el sentido que tratamos de comprender es ya el de las cosas mismas? Precisamente porque hay un orden y un devenir de las cosas mismas nuestro pensamiento puede esforzarse por comprender: los naranjos no crecen de la misma forma que los arces y hay diferencias intrínsecas entre las hormigas y los elefantes que no dependen de mi pensamiento. Cuando estudio el crecimiento de un naranjo o de un elefante no soy yo quien «crea» este objeto, lo encuentro en el mundo y procuro comprenderlo. Esto es igualmente cierto para la interpretación de los textos, donde, contrariamente a un prejuicio nietzscheano, no puede decirse todo lo que se quiera mientras se eleva una pretensión de verdad. Por lo tanto Emilio Betti ha recordado con razón el adagio hermenéutico sensus non est inferendus, sed efferendus. Para Nietzsche, como para Derrida, herederos ambos del pensamiento moderno, este sentido está siempre inscrito en el mundo y en el objeto que comprendo y que constituyo de cabo a rabo. Es el colmo del nominalismo.

\section{7. ¿NO EXISTE EN TODAS PARTES MÁS QUE LA VOLUNTAD DE PODER?}

Si Nietzsche parece dispuesto a reconocer algún estatuto a lo real, éste es el de la voluntad de poder (Wille zur Macht). En francés, no se sabe muy bien si debe traducirse el término de Macht por «potencia» (puissance) o por «poder» (pouvoir). Como el concepto de «poder» evoca connotaciones políticas indeseables, los intérpretes han preferido el término de «potencia», más estético. Es una noción que ha suscitado las interpretaciones más variopintas, a las que sería imposible pasar revista aquí. La interpretación de Heidegger no es la menos célebre, pero es audaz. Ve en ella la respuesta de Nietzsche a la cuestión de la esencia del ser (cuyo modo de existencia sería el eterno retorno): el ser no sería más que voluntad de poder, y nada más (nichts außerdem). Interpretación fuerte, que permite colocar a Nietzsche en la continuidad de la «metafísica de la voluntad», es decir, en el proyecto del pensamiento moderno que busca apoderarse del ente e incrementar su dominio sobre él, pero a costa de un olvido del ser. Los nietzscheanos han reaccionado mal, pero lo han hecho la mayoría de las veces recordando que Nietzsche, por el contrario, había siempre criticado el pensamiento metafísico (como si Heidegger lo ignorara) y que la cuestión del ser no le interesaba (como si el hecho de no tener nada que decir sobre lo que es fuera una distinción para un filósofo). Müller-Lauter ha replicado a Heidegger, en un artículo instructivo, que Nietzsche no habló nunca de la voluntad de poder en singular, sino siempre en plural: no habría voluntad de poder en sí misma, sino sólo una lucha de voluntades de poder ${ }^{17}$. Aunque no comprendo en qué se vería refutado Heidegger 
con esta réplica, la cuestión de fondo que quisiera discutir es ésta: ¿es verdad decir que todo lo real se reduce a una lucha de voluntades de poder? Podría pensarse aquí en la lucha por la supervivencia de la que había hablado Darwin. Ahora bien, es bastante gracioso constatar que Nietzsche critica a Darwin, particularmente en el Crepúsculo de los ídolos (\$14), cuando sostiene que no es verdad decir que son los más fuertes quienes sobreviven, puesto que los débiles son también muy aptos... Su Genealogía de la moral atribuye en efecto la creación de la moral al resentimiento de los débiles.

La primera cuestión que estoy tentado de plantear aquí es la siguiente: ¿hay verdaderamente sólo «débiles» y «fuertes»? ¿Hay que ver necesariamente lo real a través de este prisma? En todo caso es lícito ver en ello un reduccionismo, bastante maquiavélico y muy elitista, de lo real. Nadie discute, desde luego, que conlleva su parte de verdad y que nuestro mundo, no sólo político, esté atravesado por luchas de poderes. Eso existe, y contamina el mundo de las relaciones humanas, pero ¿qué hay de la solidaridad, la amistad, el amor y la ayuda mutua en esta visión del mundo? Nietzsche no verá en ello sin duda más que tácticas «débiles». Pero en este caso, estoy tentado de decir: iviva la debilidad!

Ahora bien, la cuestión de la verdad vuelve a cobrar actualidad aquí: ¿quién nos dice que la concepción de Nietzsche es justa? ¿No se trata también de una visión del mundo tan defendible como cualquier otra? Pero si debe poder ser confirmada por la experiencia, entonces la adecuación con lo real es posible. Y si Nietzsche sostiene razones en favor de su doctrina, es porque la considera verdadera y conforme a lo que es. Eso vendría a refutar su perspectivismo radical.

Eso podría explicar por qué hay textos donde Nietzsche parece haber revocado su tesis con respecto a la voluntad de poder. Los intérpretes han discutido mucho durante los últimos tiempos acerca de este fragmento póstumo de Nietzsche:

\section{Exotérico - esotérico \\ 1. - todo es voluntad contra voluntad \\ 2 No hay voluntad ninguna \\ 1 Causalismo \\ 2 No hay algo así como causa-efecto. \\ 1.}

Toda causalidad remite psicológicamente a la creencia en intenciones:

Precisamente el efecto de una intención es indemostrable.

(Causa efficiens es una tautología de la finalis), considerada psicológicamente $-{ }^{18}$.

Fragmento intrigante, porque Nietzsche distingue aquí una doctrina exotérica de un pensamiento más esotérico, más secreto, que podría ser el suyo. Según su doctrina exotérica $(=1)$, todo no sería más que "voluntad contra voluntad», lo que equivaldría a un «causalismo». Pero siguiendo su pensamiento más esotérico $(=2)$, no habría «en absoluto voluntad» y «nada semejante a una causa y un efecto». Se comprende lo que Nietzsche quiere decir entonces, puesto que estas dos tesis pueden encontrarse en sus textos. Si la doctrina de la voluntad de poder $(=1)$ es conocida a grandes rasgos, se encontrarán sin esfuerzo textos

18. KGW VIII/1 191: 5 [9]. Cf. al respecto H. Schmid, Nietzsches Gedanke der tragischen Erkenntnis, Würzburg: Königshausen \& Neumann, 1984. 
donde Nietzsche cuestiona más bien el proyecto, llamémoslo «metafísico», que consiste en buscar una causa de la que derivar un denominador común a lo real. Efectivamente Nietzsche ha criticado a menudo (y sin duda porque se trataba de una visión inadecuada...) tanto la «fe» en la relación de causa a efecto como la voluntad que busca reducir todo a un sujeto (Humano demasiado humano, I, \18; La gaya ciencia $\mathbb{\$} 127$, et passim). Si se ve por qué Nietzsche ha querido aprehender lo real como voluntad de poder, se adivina también por qué ha podido querer renunciar a un proyecto tal (puesto que éste sería una nueva teoría sobre lo real con pretensiones de verdad).

Aquí se plantea pues el problema de la coherencia de su pensamiento. No es un flaco desafío para las investigaciones nietzscheanas ${ }^{19}$. Una de las más atractivas soluciones a esta aporía consiste en renunciar a encontrar una coherencia última en el pensamiento de Nietzsche (con el motivo de que esta investigación sería entonces metafísica...), y a valorar el alcance más estético (si no «irónico») de su obra, saludando su concepción de la vida como literatura (Nehamas ${ }^{20}$ ) que se burla del principio de contradicción. Solución atractiva en esta era postmoderna, donde el principio de contradicción puede aparecer como una obligación lógica demasiado asfixiante, pero que no podría olvidar que esta promoción de la estética, basada en la idea de que «la existencia no está justificada más que estéticamente», sigue siendo una proposición metafísica, es decir, una respuesta a la pregunta por el sentido de la existencia y de lo que es. Si no, pierde toda pertinencia. Una lectura demasiado «literaria», ciertamente posible, corre el riesgo de privar a Nietzsche de su profundidad filosófica. Ésta aflora cuando Nietzsche evoca la cuestión del nihilismo.

\section{LA RESPUESTA DE LA HERMENÉUTICA AL NIHILISMO}

Nietzsche ha hablado con fuerza de la muerte de Dios en el célebre aforismo 125 de La gaya ciencia («El insensato», signo de que conocía bien los Salmos, y particularmente aquel que inspira a san Anselmo al comienzo de su Proslogion). Contrariamente a un prejuicio deleuziano extendido, esta muerte no es para él una fuente de júbilo, puesto que Nietzsche la presenta como un asesinato, que nos deja sin horizonte y del cual todavía no captamos todo su alcance, estando este acontecimiento todavía unterwegs, puesto que sus efectos no comienzan más que a hacerse sentir ${ }^{21}$.

No asombra que la visión perspectivista y desde entonces constructivista de Nietzsche conduzca a la muerte de Dios y de cualquier forma de lo sagrado, aunque la invocación de Dioniso conserva su nostalgia. ¿Pero esta situación es soportable? Nietzsche subraya que nos deja inconsolables (GS $\mathbb{S} 125$ : Wie trös-

19. Cf. M. Clarke, Nietzsche on Truth and Philosophy, Cambridge: Cambridge UP, 1991.

20. A. Nehamas, Nietzsche: Life as Literature, Cambridge: Harvard UP, 1985.

21. GC \ 125: El insensato: «iY nosotros lo hemos matado! ¿Cómo nos consolaremos los asesinos de todos los asesinos? Lo más sagrado y lo más poderoso que hasta ahora poseía el mundo, sangra bajo nuestros cuchillos — ¿quién nos enjugará esta sangre? [...] ¿No es la grandeza de este hecho demasiado grande para nosotros? ¿No hemos de convertirnos nosotros mismos en dioses, sólo para estar a su altura? [...] Ese enorme acontecimiento aún está en camino (noch unterwegs)». 
ten wir uns, die Mörder aller Mörder? Das Heiligste und Mächtigste, was die Welt bisher besaß, es ist unter unseren Messern verblutet - wer wischt dies Blut von uns $a b$ ?). Si conlleva un aspecto liberador, puesto que se trata de la muerte de un ídolo, Nietzsche conoce todo su dolor, terriblemente paralizante. Eso le conduce a hablar del «nihilismo» de nuestra cultura. En eso se beneficia de una actualidad hermenéutica indudable. Los grandes pensadores de la hermenéutica contemporánea como Gadamer y Ricoeur quizá han hablado demasiado poco de este espectro del nihilismo cuando han tratado del carácter histórico de la comprensión humana ${ }^{22}$. Heidegger ha captado mejor que ellos el desafío que representaba la provocación nietzscheana y el aumento del nihilismo.

¿Está la hermenéutica en condiciones de recoger este desafío? Pienso que es hora de que lo haga. La hermenéutica, al menos tal como la pienso, puede cuestionar los cimientos del nihilismo nietzscheano, enfrentándose a la vez a su constructivismo (1) y a su idea según la cual el nihilismo significaría el final de cualquier forma de fundamento, de valor y de verdad (2).

1. Para el constructivismo nietzscheano, y moderno, el sentido no sería más que una invención o una construcción que tendría que ver con nuestras interpretaciones de lo real. ¿Pero es verdad decir que no conocemos el mundo más que a través de nuestras interpretaciones? ¿Por qué no reconocer, como lo hace la sabiduría del sentido común, que podemos también conocer y recibir el mundo tal como es? ¿No se encuentra ahí la función primaria de nuestro conocimiento y de nuestro lenguaje? Ciertamente, la filosofía moderna, y nietzscheana, ha reconocido fácilmente en el conocimiento y en el lenguaje los elementos mediadores que nos «impedirían» (i!) comprender el mundo tal como es. ¿Pero hay que ver en el lenguaje tan sólo una «deformación» de lo real? No puede hablarse de «deformación» más que presuponiendo que el mundo puede ser conocido tal como es y que la misma deformación es susceptible de ser reconocida como tal. La elección me parece aquí tajante: ¿el lenguaje es la barrera que hace de pantalla al mundo o es el puente, mejor la luz, que nos permite comprender? Nietzsche opta por la primera solución, con todas las aporías que ésta comporta (autocontradicción, imposibilidad de decir algo que sea comprobable sobre lo real). La hermenéutica encuentra más evidente ver en el lenguaje el elemento mediatizante (o el medium) que nos permite hablar del ser. Aquí, "Nietzsche y la hermenéutica» expresa para mí una alternativa muy clara, una elección entre dos concepciones del sentido.

2. Esta crítica del constructivismo moderno y nietzscheano permite aportar una cierta respuesta al nihilismo contemporáneo. La idea de nihilismo sostiene que ya no hay valores ni verdades a los que estar ligados. Ahora bien, podría ser que hubiera ahí una forma de suficiencia intelectual que consiste en decir que no hay verdad o valor si no responde a nuestras normas de fundamentación última y casi cartesiana: porque no habría normas últimas fundamentadas de forma tan rigurosa, entonces no habría ya ninguna norma ni verdad. Pero esto es quedarse en una concepción muy cartesiana, y sin embargo discutida, de la verdad y del fundamento, y afirmarla.

22. Cf. mi reciente estudio «De Gadamer à Ricoeur. Peut-on parler d'une conception commune de l'herméneutique?», en G. Fiasse (dir.), Paul Ricour: De l'homme faillible à l'homme capable, Paris: PUF, 2008, pp. 37-62. 
Hay dos maneras de entender la noción de «fundamento»: a) Existe en primer lugar el fundamento que concierne a una evidencia matemática: es el fundamento que funciona como un axioma primero y absolutamente seguro del que todo lo demás se deriva con un rigor irrefutable. Cuando el nihilismo de Nietzsche proclama que ya no hay valor ni verdad, presupone una verdad fundamentada de esta manera. Pero no es la única manera como puede entenderse la idea de fundamento; $b$ ) Existe también el fundamento esencial o inmemorial sobre el que descansa toda vida, que no atañe a una fundamentación última, pero que sin embargo nos sostiene. Gadamer se ha acercado a este fundamento cuando se ha preguntado si había que fundamentar a cualquier precio aquello que nos sostenía desde siempre. Se pensará aquí en las esperas y en las esperanzas que nos atraviesan, pero también en el fundamento que puede representar, por ejemplo, la amistad, en el sentido más auténtico del término. Cuando alguien vive un momento difícil, de lo que nadie queda eximido, puede contar con un amigo o con sus amigos, los cuales le proporcionarán apoyo. iOh! No se trata entonces de un fundamento «matemático», porque si la amistad constituye la base de la vida en común, ésta no tiene nada de axiomático. Todos sabemos que la amistad puede frustrarse, traicionarse, que puede renegarse de ella, etc. Pero constituye sin embargo una fundamentación de toda vida, de la cual nos equivocaríamos al pretender que hubiese dejado de existir en la era del nihilismo. Y nadie tendría la pedantería de querer encontrar un fundamento último en la amistad. Puede también pensarse aquí en el testimonio de la fe, que quizá no gustará a todos los nietzscheanos, pero cuyo sentido estarán en condiciones de comprender. Cuando un individuo reconoce que la fe es el fundamento de toda su vida, cuando se entrega a ella, sabe perfectamente que no se trata de una fundamentación matemática. Sería igualmente ridículo esperar encontrar aquí algo semejante. Pero la fe, o la convicción fuerte que puede ser de otro orden (la lealtad, la fidelidad a la patria, a las propias convicciones, a las obligaciones), no constituye un fundamento extraordinariamente menos sólido y duradero.

Estos ejemplos no tienen como objetivo más que recordar a una época que piensa, sin razón, que la vida humana está absolutamente desprovista de fundamento o de fundamentación, que «ya nada se sostiene» y que todo queda sometido al buen deseo de cada uno, que estos fundamentos existen, pero que están quizá recubiertos por una cierta comprensión, demasiado constructiva o demasiado matemática, de la noción de fundamento y de verdad. Ninguna vida es pensable sin el fundamento que puede denominarse esencial o inmemorial, que precede y hace posible todo pensamiento y toda vida. Redescubrirlo podría ser uno de los frutos de la confrontación, polémica o amistosa, entre Nietzsche y la hermenéutica.

[Traducción de Francisco Arenas-Dolz Universidad de Valencia] 